\title{
Exploring the impact of internet gaming disorder on adolescent gamers using thematic analysis
}

\author{
Deena Balakrishnan ${ }^{1}$, Dr. Sonia George \\ ${ }^{1}$ Department of Psychology, Government College for Women, Thiruvananthapuram, Kerala, India \\ ${ }^{1}$ deenabalakrishnan@gmail.com
}

\begin{abstract}
Most of the top gaming companies are owned by China, Japan, Korea, and USA. However, the users of games, developed by these gaming techgiants are worldwide. Online/offline gaming has been a fascination for adolescents and adults ever since video games came in the global market. Moreover, Internet provides a plethora of online and offline games which help the gamers to vent out their feelings and extend resources through communication which is essential for a healthy development of emotional and psychological state. Though society often took gaming as a light hearted activity and often intended to reduce stress and boredom has recently taken a drastic shift, highlighting its negative outcomes on the users. To add on to this, the formal declaration of Internet gaming as a mental health disorder by the World Health Organization (WHO) 2018 has brought relentless researches focusing on the detrimental impact of Internet games on the users. Moreover, this inclusion has had a great influence on the scientific researches. This paper attempts to explore the impact of Internet Gaming Disorder (IGD) on adolescent gamers qualitatively using thematic analysis, and offers suggestion for combating issues pertaining to Internet games on its users.
\end{abstract}

Keywords

Internet Gaming Disorder, Adolescents, Gaming Addiction, Qualitative Analysis, Thematic Analysis

Article Received: 10 August 2020, Revised: 25 October 2020, Accepted: 18 November 2020

\section{Introduction}

According to a recent survey, India is currently ranked fifth among the list of top countries for 'game downloads' globally. Internet games provide a clear defined goal and purpose which is often missing in real life, certainty is more welcomed than uncertainty which makes the players choose games over other activities. Games give rewards which reinforces or strengthen the playability aspect. Games give a constant measurable growth making it more specific and concrete for the players about their level, their achievements and how far their goal is from their present level. It gives the player a sense of importance that of being heroic and accountable, which in turn helps many low self-esteemed individuals to feel special and important unlike their negatively perceived real life. Games also help to live one's fantasy making it more captivating for the player. Literature posits games as having direct effect on the pleasure centres of the brain. The initial investment in playing games is very less compared to any other alternative method making players prefer it over other activities requiring physical effort.

According to the Gentile et al., (2017) and Feng et al., (2017) American Psychiatric Association (APA, 2013) defines IGD in the DSM-5 as a "persistent and recurrent use of the Internet to engage in games, often with other players, leading to clinically significant impairment or distress." Thus it is a persistent pattern of engaging in online/offline games that often results in several mental health issues, ranging from tolerance build-up, to extreme withdrawal symptoms; which are very similar to substance use disorders. This makes the youth of India, extremely vulnerable to the harms associated with excessive online gaming. Various IGD studies suggested that virtual addiction such as online gaming was the most prominent Internet/cyber addiction, with researches emphasising on the clinical and motivational aspects involved in gamers, along with their personality factors. Several mental processes have been identified as predictors of online gaming addiction namely decision making and eluding thoughts. The online gaming has changed the perception about games positively as well as negatively; when a person is unable to find a balance between their online and offline game time, it may translate to mental health issues. That is, over indulgence in Internet gaming may potentially lead to addiction and other mental problems. It should be noted that addiction is both psychological and behavioral. 'Addiction' is often used to describe a persistent behavior that negatively affects the person who is addicted to substances or some sort of maladaptive behavioral patterns. That is, the addicts often succumb to their addictive behaviour detrimental effect on their lives. Thus the traditional concept of addiction, which often denoted to psychotropic substances, has now changed to behavioral addictions often labelled as "no-drug addictions" such as online gaming, viewing excessive online porn, compulsive shopping, gambling etc. As compared to substance disorders, one diagnosed with IGD prefers to spend majority of their time in front of the gadget screen often neglecting other important activities of their life including food and sleep. If they are prevented from using such gadgets or refrained from playing games, they become agitated and angry. Day to day activities, such as school and homework, or spending time with family is often compromised.

According to certain studies, the gratification experienced while engaging in addictive behaviors can be intoxicatingly euphoric. Like in any other addictive disorders, engaging in these malpractices helps eradicate tension and melancholic mood for a period until the substance or behavior is used or performed. Making it appear relatively impossible to overcome this problem. In the case of online games, the enthralling graphics and 'real' like feeling induced by these 
games makes the gamers experience an explosion of sensory pleasure in their brain centres. This complicates things further as the gamers get trapped in the games alluring features not knowing how to curb their excessive online gaming behavior which is consuming their daily life functioning.

Only a 360 degree evaluation will provide the exact scenario of gamers affected by IGD around the globe. The existing empirical review based on Internet addiction and IGD were often observed to be quantitative in nature which limits the in depth understanding of IGD as a phenomenon. Therefore, qualitatively identifying the factors contributing to IGD among adolescents will help spread awareness about IGD and take necessary precautions in the form of possible intervention strategy that can be devised to combat the disorder.

\section{Materials and methods}

The method of the present study was designed based on the research objectives, hypotheses and relevant literature related to the variables in the study. It includes details of the participants, selection of the participants, data collection process and data analysis. In order to identify participants with Internet gaming disorder the IGD scale proposed by Lemmens et al., (2015) was used to find out the respondents who met the criteria for IGD as per the guidelines set by DSM-5.

Further, the shortlisted 15 adolescents (age range 13yrs $17 y r s$ ) with high IGD scores underwent an in-depth exploration using semi structured interview. The purpose of this semi structured interview was to generate as many free responses from the participants related to their gaming behavior as possible, without deviating from the core issue; which in the present scenario happens to be gaming behavior and how it affects the gamers emotional wellbeing, critical thinking and social skills. The responses were audiotaped and transcribed and were further analyzed by means of thematic analysis; a model proposed by Braun and Clarke (2006).

\section{Result and discussion}

The codes and major themes evolved from the IGD participant's responses using thematic analysis threw light on the impact of IGD and excessive gaming on adolescent gamers' emotional wellbeing, critical thinking and social skills. The result also highlights a positive association between IGD and lockdown period due to Covid-19 and the excessive usage of Internet related platforms for gaming collectively.

The responses of the adolescent participants indicated that, they resort to games when they feel really upset or to avoid loneliness. Be it online or offline, games are often used as an escape system to vent out negative emotions or to get solace; making 'gaming' a relief for its users.

Engaging in games makes the IGD participants feel more connected with peer groups and instils a sense of belongingness. It was also observed that participants displayed intense fascination over massively multiplayer online role playing games (MMORPGs), which involved games like Freefire, PUBG, Call of Duty, World of Warcraft etc. compared to games which are designed to boost higher order thinking. These games present wide options of virtual adventures that can be played with other online gamers. This in turn helps gamers to facilitate global interaction. The gamer begins his journey as a resource less commando and gradually acquires the amenities and assets as the levels of the game progresses.

Results also indicated that family discords have also led in the prolonged usage of gaming among adolescent gamers. Various other factors such as, acceptance of likeminded others, recognition, rewarding nature of the gaming platforms and poor insight about the detrimental effects of gaming on their daily life has also contributed in the excessive gaming behavior among the IGD participants in the present study.

Insight is crucial in order for an individual to realize that one is suffering from a problem beyond one's control and they need to seek help or assistance immediately. However, in the case of online/offline gaming the whole scenario is different; gaming has become a 'social hobby' leading to a problem so common that it doesn't seem to be a problem. Nowadays, even parents are conforming to their adolescent's need to play a mobile game as long as they stay indoors rather than going out to play in the grounds. One reason for this could be that, the use of such gadgets by the adolescents are often in the presence of the parents, making these parents blindly believe that their children are under their surveillance and are therefore safe. Majority of the people are unaware of the fact that overindulgence in gaming can even result in a disorder. Due to which, these parents and their adolescents may agree to the fact that increased gaming may lead to addiction but, at the same time they may be reluctant to admit that these youngsters have a gaming addiction which may later lead to a disorder or perhaps have a disorder already. Therefore, parents are suggested to be more vigilant about their children's smart phone and computer gaming usage.

The findings of the study further emphasizes on the importance of having a healthy support system and also to have a constructive and equally entertaining hobby to overcome IGD. Apart from this, parents are suggested to encourage and provide facilities for outdoor plays to their children rather than handing them down with easy and destructive alternatives like hi-tech gadgets to spend their leisure time. However, considering the present pandemic situation, to incorporate this particular suggestion may be very challenging for the parents as it imposes danger for their adolescents of getting exposed to the novel corona virus. Nevertheless, on the long run this would be a very useful method to help their children overcome IGD to a great extent.

\section{Conclusion}

Online games were and will always be one of the most opted leisure activities by the youngsters; thus making the gaming industry ever evolving and booming. Game developers often design and market games based on the taste of new generation; as they are the potential users of this. Even the smartphone and laptop industries are marketing their new launches labelled as G-series, canvassing the gaming quotient of it as its Unique Selling Point (USP). The G- 
series are exclusively designed and engineered to meet the performance needs of budget gamers; giving the impression that, gaming is indeed the new trending thing. Although one side of the coin shows the alluring and captivating face of gaming, the other side of it is quite gruesome. Adolescence, being a vulnerable phase can be easily affected by IGD which is nothing but the by-product of gaming addiction. The qualitative approach of the present study helped to discern the impact of IGD on adolescents from the 'gamers' perspective. Adolescence, being a vulnerable phase can be easily affected by IGD; therefore creating awareness and insight amidst parents, teachers and adolescents along with timely intervention has a pivotal role in combating the IGD making it the need for the hour. Taking a step further, if game developers are creating games incorporating different, creative methods utilising the addictive nature of the games as a tool to instil life skills in its players, instead of violence and aggression; not only it is going to be a revolutionary step in changing the approach towards Internet gaming but also will be setting a milestone for the mankind itself.

\section{Acknowledgements}

I would like to thank my guiding supervisor for assisting me in my research through her valuable suggestions and remarks. I also take this opportunity to hereby confirm that no grants or funding has been received by the authors for this research work.

\section{References}

[1] Adams, H. E., \& Sutker, P. B. (2013). Comprehensive handbook of psychopathology. Springer Science \& Business Media.

[2] Allaire, J. C., McLaughlin, A. C., Trujillo, A., Whitlock, L. A., LaPorte, L., \& Gandy, M. (2013). Successful aging through digital games: Socioemotional differences between older adult gamers and nongamers. Computers in Human Behavior, 29(4),

1302-1306. https://doi.org/10.1016/j.chb.2013.01.014

[3] American Psychiatric Association. (2013). Diagnostic and statistical manual of mental disorders (DSM-5®). American Psychiatric Pub.

[4] American Psychological Association. (2015). Resolution on Violent Video Games.

http://www.apa.org/about/policy/violentvideo-games.aspx

[5] Bessière, K., Seay, A. F., \& Kiesler, S. (2007). The ideal elf: Identity exploration in world of Warcraft. CyberPsychology \& Behavior, 10(4), 530-535. https://doi.org/10.1089/cpb.2007.9994

[6] Bhayana, T. K., \& Ahuja, S. (2018). Impact of Internet Addiction on Spiritual wellbeing and Conscientiousness. International Journal of Research in Engineering, IT and Social Sciences, 8(5), 272-278.

http://www.indusedu.org/pdfs/IJREISS/IJ REISS_2533_81787.pdf

[7] Boyatzis, R. E. (1998). Transforming qualitative information: Thematic analysis and code development. SAGE.

[8] Braun, V., \& Clarke, V. (2006). Using thematic analysis in psychology. Qualitative Research in Psychology, 3(2), 77-101.

https://doi.org/10.1191/1478088706qp063 oa

[9] Braun, V., \& Clarke, V. (2012). Thematic analysis. APA handbook of research methods in psychology, Vol 2: Research designs: Quantitative, qualitative, neuropsychological, and biological, 57-71. https://doi.org/10.1037/13620-004

[10] Brevers, D., King. D.L., \& Billieux, J. (2020) Delineating adaptive esports involvement from maladaptive gaming: a self-regulation perspective 36, pp. 141-146

[11] https://www.sciencedirect.com/science/arti cle/pii/S2352250X20301378

[12] Chen, H. (2017, September 22). Internet gaming Addition (IGA) - Huankai Chen. https://huankaichen.intdes.com/uncategorized/internet-gamingadditioniga/

[13] Fathima, I. (2020, April 27). Joystick of pain, gaming addiction up 30 per cent. The New Indian Express. Retrieved May 6, 2020, from https://www.newindianexpress.com/cities/ bengaluru/2020/apr/27/joystick-of-paingaming-addiction-up-30-per-cent2135742.html

[14] Feng, W., Ramo, D. E., Chan, S. R., \& Bourgeois, J. A. (2017). Internet gaming 
disorder: Trends in prevalence 1998-2016. Addictive Behaviors, 75, 17-24. https://doi.org/10.1016/j.addbeh.2017.06.0 10

[15] Gentile, D. A., Bailey, K., Bavelier, D., Brockmyer, J. F., Cash, H., Sarah, M. C., Doan, A., Grant, S. D., $\quad$ Green, C. S., Griffiths, M. D., Nancy, T., Petry, M., Prot, S., Rae, C. D., Rehbein, F., Rich, M., Sullivan, D., Woolley, E., and Young, K. (2017). Internet Gaming Disorder in Children and Adolescents. Pediatrics November 2017, 140 (Supplement 2) S81S85;

DOI: https://doi.org/10.1542/peds.2016-1758H

[16] Griffiths, M. D. (2015). Online games, addiction and overuse of. Wiley Online Library. https://onlinelibrary.wiley.com/doi/pdf/10. 1002/9781118767771.wbiedcs044

[17] Griffiths, M. D., Kuss, D. J., LopezFernandez, O., \& Pontes, H. M. (2017). Problematic gaming exists and is an example of disordered gaming. Journal of Behavioral Addictions, 6(3), 296-301. https://doi.org/10.1556/2006.6.2017.037

[18] Kola, V. (2017, May 22). About the future of gaming in India. YourStory.com. Retrieved September 15, 2019, from https://yourstory.com/2017/05/futuregaming-india?utm_pageloadtype $=$ scroll

[19] Lau, C., Stewart, S., Sarmiento, C., Saklofske, D., \& Tremblay, P. (2018). Who is at risk for problematic video gaming? Risk factors in problematic video gaming in clinically referred Canadian children and adolescents. Multimodal Technologies and Interaction, 2(2), 19. https://doi.org/10.3390/mti2020019

[20] Lemmens, J. S., Valkenburg, P. M., \& Peter, J. (2009). Development and validation of a game addiction scale for adolescents. Media Psychology, 12(1), 7795. https://doi.org/10.1080/152132608026694 58

[21] Lemmens, J. S., Valkenburg, P. M., \& Gentile, D. A. (2015). Internet gaming disorder scale. PsycTESTS Dataset. https://doi.org/10.1037/t42759-000

[22] Lim, J., Lee, J., Jung, H. Y., Sohn, B. K., Choi, S., Kim, Y. J., Kim, D., \& Choi, J. (2016). Changes of quality of life and cognitive function in individuals with internet gaming disorder. Medicine, 95(50), e5695. https://doi.org/10.1097/md.000000000000 5695

[23] Linderoth, J., \& Bennerstedt, U. (2007). Living in World of Warcraft: The thoughts and experiences of ten young people. Göteborg University. Department of Education.

[24] Lopez-Fernandez, O. (2015). How has internet addiction research evolved since the advent of internet gaming disorder? An overview of Cyberaddictions from a psychological perspective. Current Addiction Reports, 2(3), 263-271. https://doi.org/10.1007/s40429-015-00676

[25] Lopez-Fernandez, O., Honrubia-Serrano, L., Freixa-Blanxart, M., \& Gibson, W. (2014). Mobile phone problem use scale for British adolescents. PsycTESTS Dataset. https://doi.org/10.1037/t45285000

[26] Marazziti, D., Presta, S., Baroni, S., Silvestri, S., \& Dell'Osso, L. (2014). Behavioral addictions: A novel challenge for psychopharmacology. CNS Spectrums, 19(6), 486-495. https://doi.org/10.1017/s10928529130010 41

[27] McKenna, K. Y., \& Bargh, J. A. (2000). Plan 9 from cyberspace: The implications of the internet for personality and social psychology. Personality and Social Psychology Review, 4(1), 57-75. https://doi.org/10.1207/s15327957pspr040 1_6

[28] National Youth Developmental Agency (NYDA). (2019). Education and Skills. Retrieved from http://www.nyda.gov.za/ProductsServices/Education-and-Skills 
[29] Paik, S., Cho, H., Chun, J., Jeong, J., \& Kim, D. (2017). Gaming device usage patterns predict internet gaming disorder: Comparison across different gaming device usage patterns. International Journal of Environmental Research and Public Health, 14(12), 1512. https://doi.org/10.3390/ijerph14121512

[30] Petry, N. M., \& O'Brien, C. P. (2013). Internet gaming disorder and the DSM-5. Addiction, 108(7), 1186-1187. https://doi.org/10.1111/add.12162

[31] Recovery.org.uk. (2020). Types of addictions. Retrieved July 19, 2020, from https://www.recovery.org.uk/addiction/typ es-of-addictions/

[32] Reiner, I., Tibubos, A.N., Hardt, J. et al. Peer attachment, specific patterns of internet use and problematic internet use in male and female adolescents. Eur Child Adolesc Psychiatry 26, 1257-1268 (2017). 017-0984-0 https://doi.org/10.1007/s00787-

[33] Singh, S., Dahiya, N., Singh, A., Kumar, R., \& Balhara, Y. S. (2019). Gaming disorder among medical college students from India: Exploring the pattern and correlates. Industrial Psychiatry Journal, 28(1), 107. https://doi.org/10.4103/ipj.ipj_96_18

[34] Starcevic, V., \& Khazaal, Y. (2017). Relationships between behavioural addictions and psychiatric disorders: What is known and what is yet to be learned? Frontiers in Psychiatry, 8. https://doi.org/10.3389/fpsyt.2017.00053

[35] Vagus, A. (2019, September 7). How to overcome addiction using law of attraction - Your Alpha dude. - Be Masculine and live a life of freedom. https://www.youralphadude.com/law-ofattraction-to-overcome-addiction/ 